\title{
Copenhagen Accord Pledges imply higher costs for staying below $2^{\circ} \mathrm{C}$ warming
}

\author{
Jasper van Vliet ${ }^{a}$, Maarten van den Berg ${ }^{a}$, Michiel Schaeffer ${ }^{c}$, Detlef P. van Vuuren ${ }^{a, b}$, Michel \\ den Elzen ${ }^{a}$, Andries F. Hof ${ }^{a}$, Angelica Mendoza Beltran ${ }^{a}$, Malte Meinshausen ${ }^{d, e}$ \\ ${ }^{a}$ Climate, Air and Energy, Netherlands Environmental Assessment Agency, P.O. Box 303, 3720 \\ AH Bilthoven, The Netherlands; ${ }^{b}$ Utrecht University, Faculty of Geosciences, ${ }^{c}$ Climate Analytics \\ GmbH, Telegrafenberg A26, 14473 Potsdam, Germany; ${ }^{d}$ PRIMAP Group, Earth System \\ Analysis, Potsdam Institute for Climate Impact Research (PIK), PO Box 6012 03, 14412 \\ Potsdam, Germany; ${ }^{e}$ School of Earth Sciences, The University of Melbourne, Victoria 3010, \\ Australia.
}

\begin{abstract}
This study compares emission pathways aimed at limiting temperature increase to $2^{\circ} \mathrm{C}$ under varying constraints. In a first set of pathways, the timing of emission reductions is such that over the 2010-2100 period, assuming full participation from 2013 onwards, costs are minimized. In a second set of pathways, we set emissions in 2020 at a level based on the pledges of the Copenhagen Accord. In the 'Copenhagen Potential' scenario, climate talks result in satisfying conditions linked by countries to their 'most ambitious' proposals. Contrasting, in the 'Copenhagen Current' scenario, climate talks fall short of satisfying the conditions to move beyond current unilateral pledges. We include scenarios with and without the availability of bioenergy in combination with carbon capture and storage. We find that for a 'Copenhagen Potential' scenario, emissions by 2020 are higher $\left(47 \mathrm{GtCO}_{2} \mathrm{eq} / \mathrm{yr}\right)$ than for a least-cost pathway for $2^{\circ} \mathrm{C}\left(43 \mathrm{GtCO}_{2} / \mathrm{yr}\right.$ with a $40-46 \mathrm{GtCO}_{2} \mathrm{eq} / \mathrm{yr}$ literature range). In the 'Copenhagen Potential' scenario the $2^{\circ} \mathrm{C}$ target can still be met with a likely chance, although discounted mitigation costs over 2010-2100 could be 10 to $15 \%$ higher, and up to 60\% in the 2040-2050s, than for least-cost pathways. For the 'Copenhagen Current' scenario, maintaining an equally low probability of exceeding $2^{\circ} \mathrm{C}$ becomes infeasible in our model, implying higher costs due to higher climate risks. We conclude that there is some flexibility in terms of 2020 emissions compared to the optimal pathways but this is limited. The 2020 emission level represents a trade-off between short-term emission reductions, long-term dependence on rapid reductions through specific technologies (like negative emission reductions). Higher 2020 emissions lead to higher overall costs and reduced long-term flexibility, both leading to a higher risk of failing to hold warming below $2^{\circ} \mathrm{C}$.
\end{abstract}

\section{Introduction}

The Copenhagen Accord, the Cancún Agreements and the Durban Platform all indicate that international climate policy should consider reducing global greenhouse gas emissions so as to hold the increase in global temperature below $2^{\circ} \mathrm{C}$ above pre-industrial levels (UNFCCC, 2009; 2010c; 2011). As part of the same process, a set of short-term emission reduction proposals and actions have been submitted by individual countries in the form of reduction pledges (UNFCCC, 2010a; 2010b). A crucial question is whether these pledges are consistent with a long term $2^{\circ} \mathrm{C}$ temperature target.

Several studies have looked into this question, such as Rogelj et al. (2010; 2011), IEA (2010), den Elzen et al. (2010), Nordhaus (2010) and UNEP (2010; 2011). In general, these studies concluded that the Copenhagen pledges result in global 2020 emission levels well above those consistent with literature scenarios that lead to reaching the $2^{\circ} \mathrm{C}$ target with a high chance (based on the uncertainty in climate sensitivity). Of these studies, the UNEP Emissions Gap Reports 
(UNEP, 2010, 2011) provide a comprehensive and detailed analysis of i) the 2020 emission levels consistent with least-cost $2^{\circ} \mathrm{C}$ emission pathways as published in the scientific literature, and ii) the expected global greenhouse gas emission levels resulting from the Copenhagen Accord pledges. The UNEP reports introduced the notion of the 'emission gap' as the difference between the 2020 emission levels derived from least-cost scenarios that are consistent with the $2{ }^{\circ} \mathrm{C}$ target and the emission levels resulting from the Copenhagen Accord pledges.

In this context, the main question of this paper is whether a delayed response, starting from the 2020 emission pledges, would still allow a long-term scenario with a medium (50 to 66\%) or likely (>66\%) probability of reaching the $2^{\circ} \mathrm{C}$ target, and if so, what the additional costs could be. Our analysis combines long term emission reductions potentials with a detailed interpretation of pledges made under the Copenhagen Accord.

\section{Methods}

\subsection{Modeling framework}

We use the Integrated Assessment model FAIR-SiMCaP ${ }^{1}$ (den Elzen et al., 2007a) and the MAGICC 6 climate model (Meinshausen et al., 2011a) to calculate long-term emission pathways. These pathways are determined by minimizing cumulative discounted mitigation costs under specific, user-determined, criteria such as long-term climate targets and 2020 emission levels. The FAIR-SiMCaP model uses regional information on baseline emissions ${ }^{2}$ and marginal abatement cost (MAC) curves from the IMAGE land use and TIMER energy model (Bouwman, 2006; van Vuuren, 2007). The MAC curves take into account all major emission abatement options, including reducing non- $\mathrm{CO}_{2}$ gases, carbon plantations, carbon capture and storage (CCS), bio-energy, and energy efficiency improvements (van Vuuren, 2007). In order to capture the time and pathway dependent dynamics (due to technology learning and inertia related to capital-turnover rates) of the underlying expert models, MAC curves are derived for different reduction pathways and scaled in the FAIR model based on the actual implementation. Similarly, emission reduction rates are limited to the maximum reduction rates found in the expert model ${ }^{3}$ and also the rate at which emissions can change from an increase to actual reductions is limited (see den Elzen et al., 2010 and SI). The model limits the MACs to $270 \$ / \mathrm{tCO}_{2}(1000 \$ / \mathrm{tC})$ as little information in literature can be found on reduction potential at higher prices. For the climate calculations, , FAIR-SiMCaP uses the MAGICC 6 model, with parameter settings calibrated to reflect the median response to the RCP scenario emissions of a range of both coupled general circulation climate models and carbon-cycle models (Meinshausen et al, 2011a, 2011b). All references to forcing levels and concentrations in this paper are based on this "representative" model version. In addition to the standard "single-run" MAGICC 6 version, we also use the "illustrative default" Monte-Carlo simulation setup described in Meinshausen et al. (2009) to ex-post estimate the probability for each pathway of achieving climate targets during the $21^{\text {st }}$ century. In this setup, MAGICC 6 is run 600 times for each emission scenario, each time with different climate-model parameter settings. The proportion of the 600 Monte-Carlo runs in

\footnotetext{
${ }^{1}$ Framework to Assess International Regimes for the differentiation of commitments - Simple Model for Climate Policy Assessment

${ }^{2}$ Emissions in this paper refer to the sum of the six Kyoto greenhouse gas emissions $\left(\mathrm{CO}_{2}\right.$ equivalent emissions weighted by global warming potentials as presented in the IPCC Fourth Assesment Report (Solomon et al., 2007)) as listed in Annex A of the Kyoto Protocol and include land-use related CO2 emissions

${ }^{3}$ An annual reduction rate of $3.5-4.5 \%$ of 2000 emission levels, applied to Kyoto greenhouse gases excluding land use $\mathrm{CO}_{2}$, for respectively with and without bio-energy with CCS (BECCS) technology. The potential reduction rate with BECCS is higher because this technology results in net negative emissions, as it replaces fossil fuels with biomass and captures and stores the $\mathrm{CO}_{2}$ from combustion.
} 
which the temperature target was not exceeded is used to indicate the probability of staying below the $2^{\circ} \mathrm{C}$ target.

\subsection{Scenario setup}

The baseline (i.e. the scenario without climate policy) applied in this analysis represents a medium emission scenario, partly calibrated on the IEA World Energy Outlook 2007 (IEA, 2007). It is described more extensively in van Vuuren et al. (2010). Kyoto targets are assumed to be reached by all developed countries except the USA, and reductions are not part of the baseline (see SI). For six policy scenarios derived from the baseline, we analyse the additional costs of delayed emission reductions, either in terms of the additional costs of reaching the same 2100 target or, if the target is not achievable, in terms of the reduced probability of reaching the $2{ }^{\circ} \mathrm{C}$ target (Table 1). The first two scenarios are the reference scenarios with least-cost pathways without additional restrictions on the emission level in 2020. These scenarios reach the long-term target while minimizing cumulative discounted mitigation costs over 2010-2100. The other four scenarios differ in the assumptions on 1) implementation of the Copenhagen Accord pledges, 2) the availability of negative emission technology, and 3) the level of the long-term climate target. Starting from prescribed 2020 emission levels, the scenarios aim to satisfy the long-term target while minimizing cumulative discounted costs over 2020-2100. In all scenarios, we assume that net $\mathrm{CO}_{2}$ emissions from land use and land-use change linearly decline to zero between 2020 and 2050 , as a result of mitigation actions proposed by major deforesting countries (See SI).

\section{Copenhagen Accord Pledges}

For the Copenhagen Accord Pledges scenarios, the 2020 emission reductions are based on den Elzen et al. (2011), but revised to reflect the assumed (lower) baseline emissions in this study (see SI). Several countries have formulated their pledges conditional on action of other countries or financing by developed countries. Therefore, we consider two scenarios: the 'Copenhagen Potential' scenario in which countries implement their most ambitious pledges, subject to strict accounting rules (only land use accounting ${ }^{4}$, no carry-over of Kyoto surpluses and $25 \%$ trade of new surpluses) and the 'Current Copenhagen' scenario in which countries implement their least ambitious unilateral pledges, subject to lenient accounting rules (land use accounting, 50\% carryover and trade/use of Kyoto surpluses and 50\% trade of new surpluses for compliance purposes). The Copenhagen Potential scenario leads to global greenhouse gas emissions of $47.1 \mathrm{GtCO}_{2} \mathrm{eq}$ by 2020 (including land use $\mathrm{CO}_{2}$ and international aviation and marine emissions), which is a $11 \%$ reduction below baseline levels. The Current Copenhagen scenario leads to a global emission level of $51.4 \mathrm{GtCO}_{2}$ eq, which is $2 \%$ below baseline (details in SI).

\section{Availability of negative emissions}

The option of negative emissions as can be realized by the combination of bio-energy and carbon capture and storage (BECCS) in the second half of the century can have important implications for short-term emission reductions (van Vuuren and Riahi, 2011). The use of BECCS does not only depend on the physical potential for bio-energy and storage but also on the societal acceptance of these technologies. Given these uncertainties, we have looked at scenarios with and without the option of BECCS. It should be noted that not only the timing, but also costs of mitigation are influenced by the availability of this technology. We assume no change in land-use related emissions under the BECCS scenarios because part of the bioenergy for BECCS replaces

\footnotetext{
${ }^{4}$ The Joint Research Centre has calculated the estimated credits accounting for land use and forestry for all Annex I countries, as described in den Elzen et al. (2011), which would result in additional emission allowances of $2.5 \%$ of 1990 Annex I emissions (about $0.5 \mathrm{GtCO}_{2}$ eq) by 2020.
} 
previous bio-energy use. In the modeling framework, significant use of agricultural residues for bio-energy production and no deforestation for biofuel production is assumed. (See SI).

\section{Ambition of long-term target}

This paper considers pathways reaching 2.6 and $2.9^{5} \mathrm{~W} / \mathrm{m}^{2}$ when feasible ${ }^{6}$, and calculates the probability of global temperature rise to not exceed $2^{\circ} \mathrm{C}$ for each of these pathways. The scenario setup allows overshoot of concentration and radiative forcing levels before 2100. As den Elzen et al. (2007b) and Johansson (2011) show, this does not automatically leads to overshoot of a $2^{\circ} \mathrm{C}$ temperature target. In our model, a $2.6 \mathrm{~W} / \mathrm{m}^{2}$ target by 2100 is only feasible with BECCS. The target of the optimal and Copenhagen Potential scenario without BECCS is set at $2.9 \mathrm{~W} / \mathrm{m}^{2}$. For the Current Copenhagen scenarios, 2.6 and $2.9 \mathrm{~W} / \mathrm{m}^{2}$ targets are not feasible in our framework. We therefore set the targets at the lowest feasible forcing levels, which is $3.2 \mathrm{~W} / \mathrm{m}^{2}$ without and $2.8 \mathrm{~W} / \mathrm{m}^{2}$ with BECCS). In these cases, the costs of the delay in emission reduction are not only monetary, but also consists of a reduction of the probability in reaching the $2{ }^{\circ} \mathrm{C}$ target.

Table 1. Overview of scenario design.

\begin{tabular}{|l|l|l|l|l|}
\hline Scenario name & Copenhagen & $\begin{array}{l}\text { Optimal } \\
\text { pathway start } \\
\text { year }\end{array}$ & BECCS & $\begin{array}{l}\text { End target } \\
\left(\mathbf{W} / \mathbf{m}^{2}\right)\end{array}$ \\
\hline Optimal 2.9 W/m & & 2010 & No & 2.9 \\
\hline $\begin{array}{l}\text { Optimal BECCS 2.6 } \\
\text { W/m }\end{array}$ & No & 2010 & Yes & 2.6 \\
\hline $\begin{array}{l}\text { Copenhagen Potential } \\
\mathbf{2 . 9} \mathbf{W} / \mathbf{m}^{2}\end{array}$ & $\begin{array}{l}\text { Conditional } \\
\text { pledges, strict } \\
\text { accounting }\end{array}$ & 2020 & No & 2.9 \\
\hline $\begin{array}{l}\text { Copenhagen Potential } \\
\text { BECCS 2.6 W/m }\end{array}$ & $\begin{array}{l}\text { Conditional } \\
\text { pledges, strict } \\
\text { accounting }\end{array}$ & 2020 & Yes & 2.6 \\
\hline $\begin{array}{l}\text { Current Copenhagen } \\
\mathbf{3 . 2} \mathbf{W} / \mathbf{m}^{2} *\end{array}$ & $\begin{array}{l}\text { Unilateral pledges, } \\
\text { lenient accounting }\end{array}$ & 2020 & No & 3.2 \\
\hline $\begin{array}{l}\text { Current Copenhagen } \\
\text { BECCS 2.8 W/m }\end{array}$ & $\begin{array}{l}\text { Unilateral pledges, } \\
\text { lenient accounting }\end{array}$ & 2020 & Yes & 2.8 \\
\hline
\end{tabular}

*: The given radiative forcing levels are the lowest for which the model would solve under the assumed 2020 emission levels. The $2.9 \mathrm{~W} / \mathrm{m}^{2}$ and $2.6 \mathrm{~W} / \mathrm{m}^{2}$ targets are infeasible under these conditions and in the applied model version. Note: As indicated in the text, the forcing levels used to name each of the pathways refer to the 2100 forcing level reached in the standard MAGICC 6 version used in FAIR-SiMCaP.

\section{Results}

Our pathways show that reaching 2.6 and $2.9 \mathrm{~W} / \mathrm{m}^{2}$ targets are feasible starting from the Potential Copenhagen Accord pledges in 2020, which implies that the higher emission level by 2020 is compensated for in the long run. The compensation leads to higher cumulative discounted costs over 2010-2100 (by 10 to 15\%) compared to the cost-optimal case. In the current modeling framework this is only possible for scenarios that allow the use of BECCS, which makes it easier to compensate for the higher short-term emissions. Short-term costs,

\footnotetext{
5 There is considerable uncertainty regarding exact radiative forcing levels of gases (see Forster et al., 2007). The forcing levels reported here include all anthropogenic forcings under a best-estimate climate model setting (see Meinshausen et al., 2011a).

${ }^{6}$ A scenario is considered feasible if there is sufficient mitigation potential available to meet the climate target at all times during the evaluation period, at carbon prices below $1000 \$ / \mathrm{tC}$.
} 
however, are lower as less mitigation is taking place during the 2010-2030 period. Another important finding is that in the current model, further postponing emission reductions to the level of the Current Copenhagen scenario inhibits reaching the radiative forcing levels reached by the other scenarios (Figure 1, middle row). The lowest achievable 2100 levels are 2.8 and $3.2 \mathrm{~W} / \mathrm{m}^{2}$, respectively for the scenario with and without BECCS.

The availability of BECCS is the key determinant for 2100 emission levels. For scenarios without BECCS, 2100 emission levels are $11 \mathrm{GtCO}_{2} \mathrm{eq} / \mathrm{yr}$, whereas scenarios with BECCS reach $4 \mathrm{GtCO}_{2} \mathrm{eq} / \mathrm{yr}$ (Figure 1, top row). The unconstrained, cost-optimal pathways (assuming full participation from 2013) reach a level of around $44 \mathrm{GtCO}_{2} \mathrm{eq} / \mathrm{yr}$ by 2020 , which is within the literature range of 40-46 $\mathrm{GtCO}_{2} \mathrm{eq} / \mathrm{yr}$ (Rogelj et al., 2011). The 2020 emission levels of the Copenhagen Potential scenarios are with $47.1 \mathrm{GtCO}_{2} \mathrm{eq} / \mathrm{yr}$ about $3 \mathrm{GtCO}_{2} \mathrm{eq} / \mathrm{yr}$ above the optimal pathways. The Current Copenhagen scenarios reach emission levels of $7 \mathrm{GtCO}_{2} \mathrm{eq} / \mathrm{yr}$ above this level. This compares to a global emission level in 2010 of $44 \mathrm{GtCO}_{2}$ eq in our model, while actual emissions could be as high as $49 \mathrm{GtCO}_{2}$ eq in 2009.(cf. Montzka et al. 2011 ${ }^{7}$ ). This would not necessarily change our estimates of 2020 emission levels, but could imply more compensatory mitigation actions thereafter.

The 2020 emission levels of the pathways do affect the 2050 emission levels, but in general, the emission levels of the scenarios all convergence to very similar levels by 2100 (although to different levels for scenarios with and without BECCS). At that time, the model uses (nearly) its full mitigation potential. In fact, for several sources emissions cannot be reduced to zero given the lack of identified reduction measures (e.g. $\mathrm{CH}_{4}$ emissions from animal production and $\mathrm{N}_{2} \mathrm{O}$ emissions from the use of fertilizers, see Lucas et al. (2007)). This reiterates the role of early and medium term mitigation action due to the limitation of compensation in the long term.

\footnotetext{
${ }^{7}$ Note that our reported total emissions comprise all GHG emissions of gases controlled under the Kyoto Protocol, and Ozon Depleting Substances (ODS) emissions are dealt with separately in our climate model. Total emission levels reported in Montzka et al. (2011) include ODS controlled under the Montreal Protocol, and higher $\mathrm{CO}_{2}$ emissions from land use. This explains about $3 \mathrm{Gt} \mathrm{CO}_{2}$ eq of the difference.
} 


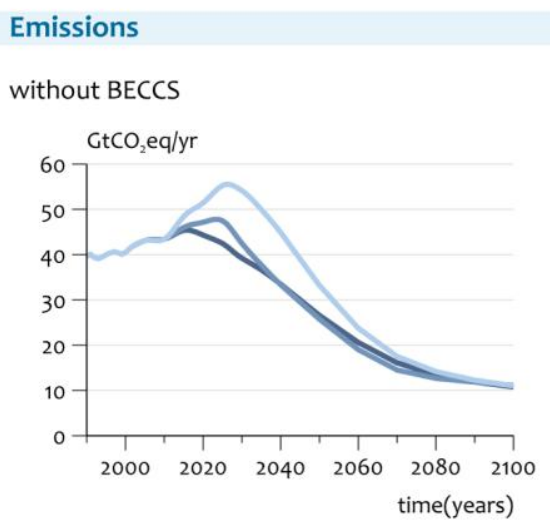

with BECCS

\section{Radiative forcing}

without BECCS

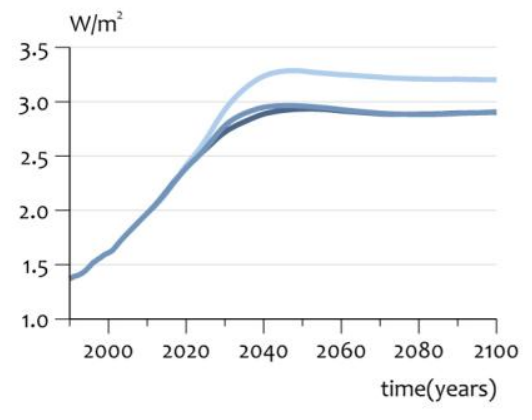

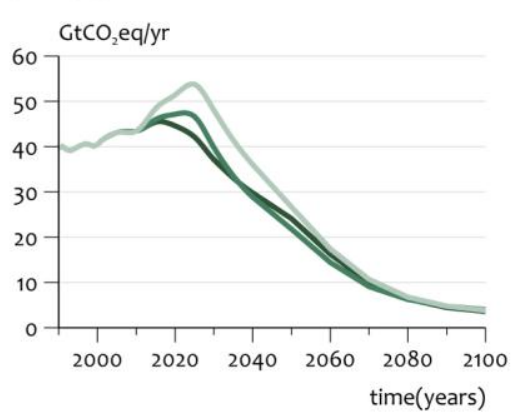

Global mitigation costs

without BECCS

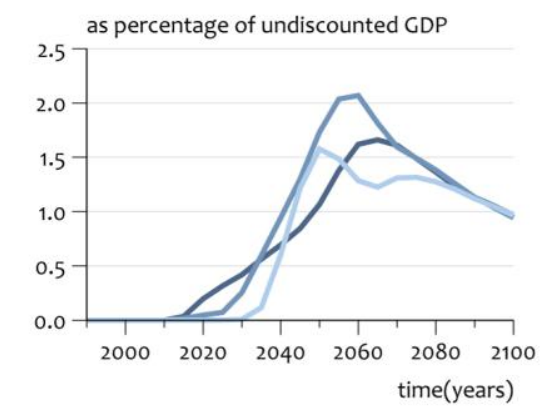

- optimal $2.9 \mathrm{~W} / \mathrm{m}^{2}$

- Potential Copenhagen $2.9 \mathrm{~W} / \mathrm{m}^{2}$

- Current Copenhagen $3.2 \mathrm{~W} / \mathrm{m}^{2}$

\section{with BECCS}

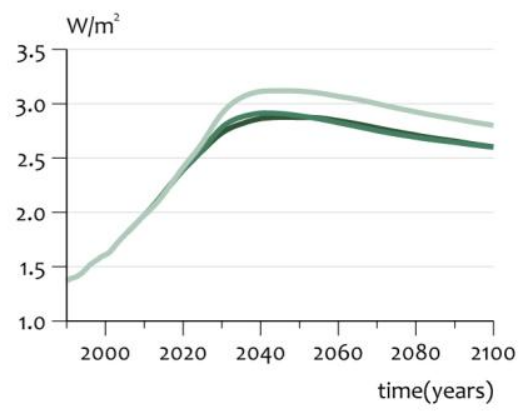

Figure 1, Scenario results describing Kyoto greenhouse gas emissions including land use $\mathrm{CO}_{2}$ (top row), radiative forcing including all gases and aerosol forcings (middle row) and global mitigation costs as percentage of GDP (bottom row). The left column shows results for scenarios without BECCS and the right column shows results including BECCS. 
Table 2 Characteristics of global emission pathways (all Kyoto greenhouse gas incl. land use $\mathrm{CO}_{2}$ )

\begin{tabular}{|l|l|l|l|l|c|}
\hline Scenario name & $\begin{array}{l}2020 \\
\text { emissions }\end{array}$ & $\begin{array}{l}2050 \\
\text { emissions }\end{array}$ & $\begin{array}{l}\text { Date of } \\
\text { peaking } \\
\text { emissions }\end{array}$ & $\begin{array}{l}\text { Cumulative } \\
\text { discounted } \\
\text { mitigation } \\
\text { costs, 2010- } \\
2100\end{array}$ & $\begin{array}{l}\text { Probability } \\
\text { to not } \\
\text { exceed } 2{ }^{\circ} \mathrm{C} \\
\text { by 2100 }\end{array}$ \\
\hline $\mathrm{GtCO}_{2} \mathrm{eq}$ & $\mathrm{GtCO}_{2} \mathrm{eq}$ & Year & $\begin{array}{c}\text { Trillion } \\
\text { 2005 US\$ }\end{array}$ & $\%$ \\
\hline Optimal 2.9 W/m ${ }^{2}$ & 44.3 & 26.6 & 2016 & 10.6 & 59 \\
\hline $\begin{array}{l}\text { Optimal BECCS 2.6 } \\
\text { W/m }\end{array}$ & 44.6 & 24.1 & 2016 & 11.5 & 73 \\
\hline $\begin{array}{l}\text { Copenhagen } \\
\text { Potential 2.9 W/m }\end{array}$ & 47.1 & 25.7 & 2024 & 12.1 & 58 \\
\hline $\begin{array}{l}\text { Copenhagen } \\
\text { Potential BECCS 2.6 } \\
\text { W/m }\end{array}$ & 47.1 & 21.8 & 2022 & 12.9 & 73 \\
\hline $\begin{array}{l}\text { Current Copenhagen } \\
3.2 \mathrm{~W} / \mathrm{m}^{2}\end{array}$ & 51.4 & 33.2 & 2026 & 9.2 & 37 \\
\hline $\begin{array}{l}\text { Current Copenhagen } \\
\text { BECCS 2.8 W/m }\end{array}$ & 51.4 & 26.7 & 2024 & 10.7 & 60 \\
\hline
\end{tabular}

For the Copenhagen Potential pathways it is possible to reach the same long-term targets as in the optimal pathways. The associated risk of temperature rise not exceeding $2^{\circ} \mathrm{C}$ is similar to the optimal pathways (see Table 2 and Figure 2), despite the small differences in concentration during the $21^{\text {st }}$ century, as a result of climate system inertia. The Current Copenhagen scenarios fail to reach the $2^{\circ} \mathrm{C}$ target, due to lack of mitigation potential, so that the higher short-term emissions cannot be compensated for. As a result, the costs translate into a $50 \%$ relative increased risk of exceeding $2^{\circ} \mathrm{C}$. The chance to exceed $2.5^{\circ} \mathrm{C}$ even doubles in the Current Copenhagen cases (see SI).

Finally, a comparison of the scenarios with and without BECCS in Table 2 show the influential role of BECCS in increasing the probability of not exceeding the $2^{\circ} \mathrm{C}$ target at very small additional costs (see also Azar et al. (2010) for three integrated assessment models results). Figure 2 shows that only scenarios with targets of 2.6 and $2.8 \mathrm{~W} / \mathrm{m}^{2}$ (green lines in Figure 2) achieve a stabilization or slow decline in warming by the year 2100 , while all scenarios without BECCS (blue lines in Figure 2) lead to a considerable rate of temperature increase by that time (about $0.05^{\circ} \mathrm{C} / \mathrm{yr}$, which is a quarter of today's rate of global warming). A higher rate of temperature increase by 2100 implies a potentially continuing divergence in warming - and therefore a higher chance to exceed $2^{\circ} \mathrm{C}$ after 2100 . 


\section{Global-mean temperature increase above pre-industrial}

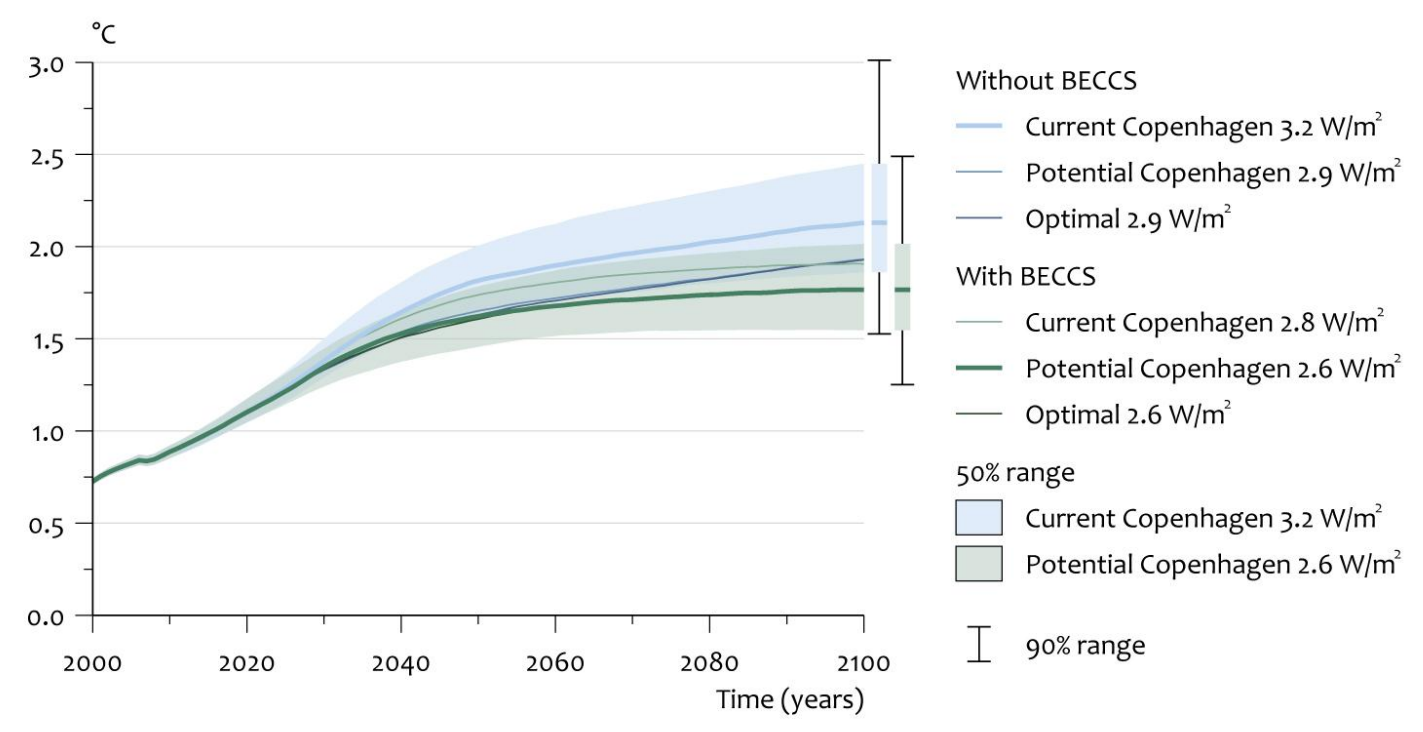

Figure 2, Probabilistic climate-model projections of global-mean temperature increase above preindustrial levels. Median projections (solid lines) are shown for the six scenarios listed in table 2. The $50 \%$ uncertainty ranges are provided for two scenarios: the highest no-BECCS scenario (blue) and lowest Current Copenhagen scenario (green). The bars on the right-hand side provide 90\% uncertainty ranges for these two scenarios, in addition to their medians and $50 \%$ ranges for the year 2100.

\section{Sensitivity analysis on discounting}

The optimal emission pathways in this paper aim at minimizing cumulative discounted costs over the 2010 to 2100 period. For this cost metric, discounting is an important factor. Higher discount rates give an incentive for delaying mitigation. We have explored a series of constant discount rates to study the effect of discounting on the timing of emission reductions (considering mitigation costs only; cost-benefit analysis are not performed). 


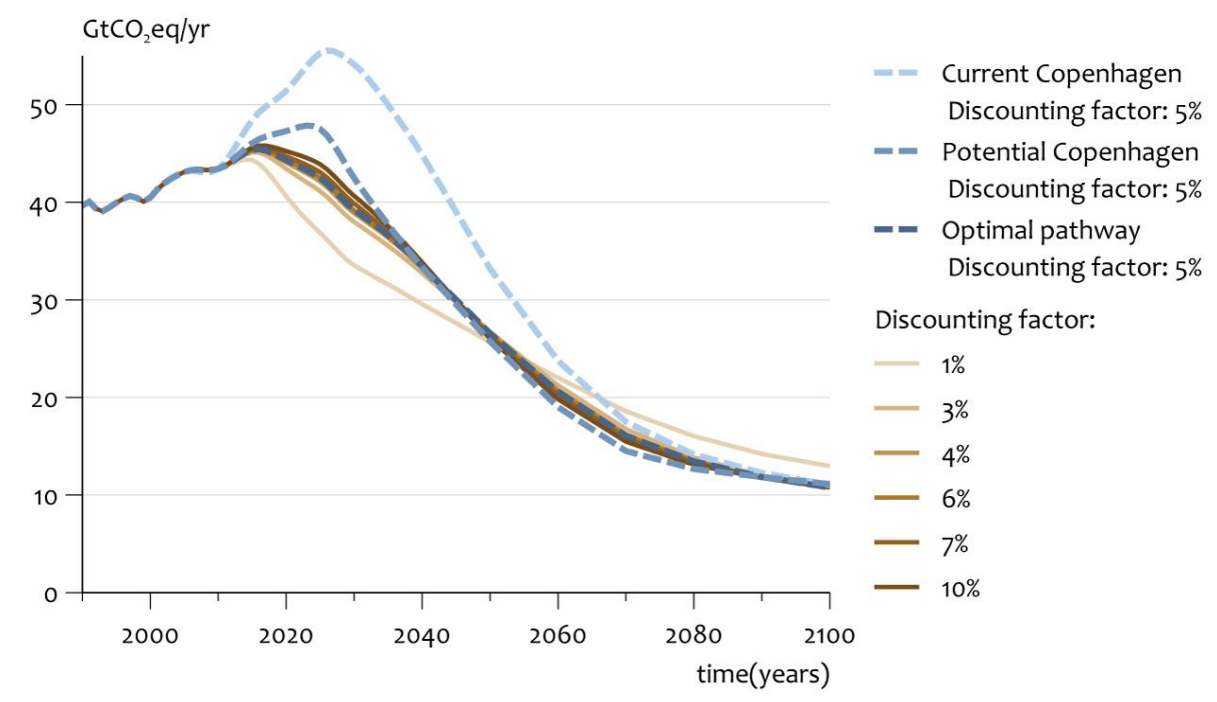

Figure 3, Least cost emission pathways (all Kyoto greenhouse gas incl. land use $\mathrm{CO}_{2}$ ) under varying discount rates.

\section{Global emission pathways under different discount rates}

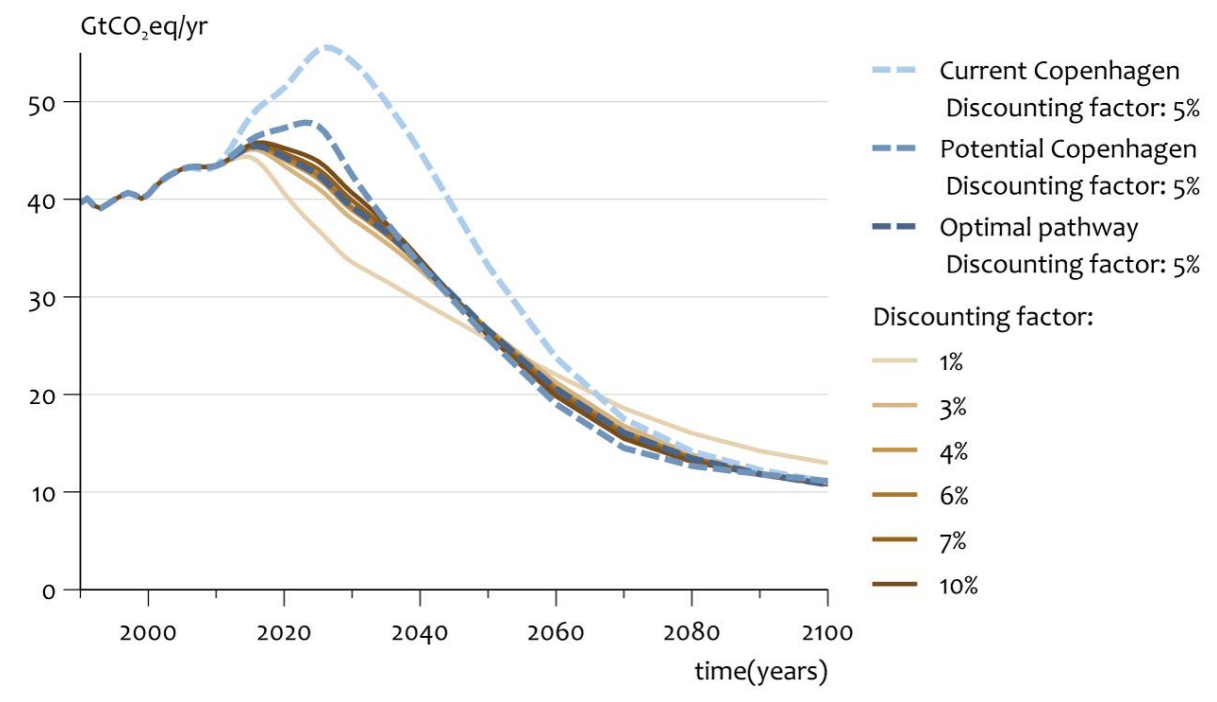

Figure 3 shows $2.9 \mathrm{~W} / \mathrm{m}^{2}$ climate target pathways with varying discount rates, as well as the optimal and Copenhagen scenarios presented earlier for comparison (Figure 1, top left). In all cases, emissions by 2020 for the Copenhagen pathways remain 2 to $6 \mathrm{GtCO}_{2} \mathrm{eq} / \mathrm{yr}$ above the range of least cost pathways generated by the range of discount rates. Therefore, the conclusion that Copenhagen Accord pledges are above the cost-optimal pathway is robust.

\section{Conclusions and discussion}


From the pathways analyzed within the applied integrated modeling framework it can be concluded that:

- The global 2020 emission level resulting from the implementation of the Copenhagen Accord pledges are above those of least-cost pathways that achieve a $2^{\circ} \mathrm{C}$ target. This was shown earlier by UNEP (2010; 2011) and Nordhaus (2010). Such least-cost scenarios with full participation seem increasingly at odds with the current policy situation - or vice versa - the policy situation seems to be increasingly at odds with least cost pathways to achieve the $2^{\circ} \mathrm{C}$ target.

- Somewhat postponing mitigation action compared to the least-cost scenario seems technically possible, although at higher cumulative discounted mitigation costs of 10 to $15 \%$ during the $21^{\text {st }}$ century. An ambitious implementation of the Copenhagen Accord results in a global emission level of around $47 \mathrm{GtCO}_{2} \mathrm{eq} / \mathrm{yr}$ by 2020 (den Elzen et al, 2011). Such a level, combined with increased mitigation efforts thereafter (resulting in up to $60 \%$ higher mitigation costs during the 2040s/50s) would still allow a likely chance to stay below $2{ }^{\circ} \mathrm{C}$. This emission level is above the the range derived from cost-optimal pathways (43 $\mathrm{GtCO}_{2} \mathrm{eq} / \mathrm{yr}$ in this study and 40-46 $\mathrm{GtCO}_{2} \mathrm{eq} / \mathrm{yr}$ according to UNEP, 2010; Rogelj et al., $2011)^{8}$.

- For even more delay (the current Copenhagen scenario) the FAIR-SiMCaP model cannot fully compensate for the higher short-term emissions. This translates into a lower probability to reach the $2^{\circ} \mathrm{C}$ target. In other words, there is a cost to delay either in terms of mitigation costs or reduced probability of achieving the target. With increasing long-term ambition it becomes increasingly problematic to compensate for the slower start.

- A delay in emission reductions limits the flexibility in the portfolio of emission reduction options. Such delayed scenarios rely more on the use of BECCS, of which large-scale implementation is far from certain. In determining near-term targets, benefits of negative emissions (reduced costs, lower required near-term emission reductions) need to be evaluated against the risk of this limitation in the mitigation technology portfolio. Also assumptions concerning the availability of mitigation potential and technologies (e.g. Edenhofer et al., 2010) and the participation of countries in a global climate regime (e.g. Clarke et al., 2009) are important factors for the feasibility, costs and risks of climate policy.

- Significant emission reductions are required in 2020 to keep the option of reaching the $2{ }^{\circ} \mathrm{C}$ target open. As such, efforts to keep global emissions by 2020 below the current Copenhagen scenario remain pressing if one aims to achieve the $2^{\circ} \mathrm{C}$ target with medium or likely probability.

\section{References}

Azar, C., K. Lindgren, M. Obersteiner, et al. (2010). "The feasibility of low CO2 concentration targets and the role of bio-energy with carbon capture and storage (BECCS)." Climatic Change 100(1): 195-202.

Bouwman, A. F., Kram, T., Klein_Goldewijk, K. (2006). Integrated modelling of global environmental change. An overview of IMAGE 2.4. Bilthoven, The Netherlands, Netherlands Environmental Assessment Agency.

den Elzen, M., M. Meinshausen and D. van Vuuren (2007a). "Multi-gas emission envelopes to meet greenhouse gas concentration targets: Costs versus certainty of limiting temperature increase." Global Environmental Change 17(2): 260-280.

\footnotetext{
${ }^{8}$ Note that our estimates - in contrast with the UNEP figures - are based on non-harmonized historical data. With harmonization, the optimal emission level would be about $1 \mathrm{GtCO}_{2}$ eq higher by 2020 (also see SI)
} 
den Elzen, M. G. J. and D. P. Van Vuuren (2007b). "Peaking profiles for achieving long-term temperature targets with more likelihood at lower costs." Proceedings of the National Academy of Sciences of the United States of America 104(46): 17931-17936.

den Elzen, M. G. J., D. P. van Vuuren and J. van Vliet (2010). "Postponing emission reductions from 2020 to 2030 increases climate risks and long-term costs." Climatic Change 99(1): 313-320.

den Elzen, M. G. J., A. F. Hof and M. Roelfsema (2011). "The emissions gap between the Copenhagen pledges andthe $2 \mathrm{C}$ climate goal: Options for closing and risks that could wident he gap." Global Environmental Change(21): 733-743.

Edenhofer, O., B. Knopf, T. Barker, et al. (2010). "The economics of low stabilization: Model comparison of mitigation strategies and costs." Energy Journal 31(SPECIAL ISSUE): 11-48.

Forster, P., V. Ramaswamy, P. Artaxo, T. Berntsen, R. Betts, D.W. Fahey, J. Haywood, J. Lean, D.C. Lowe, G. Myhre, J. Nganga, R. Prinn, G. Raga, M. Schulz and R. Van Dorland (2007). Changes in Atmospheric Constituents and in Radiative Forcing. In: Climate Change 2007: The Physical Science Basis. Contribution of Working Group I to the Fourth Assessment Report of the Intergovernmental Panel on Climate Change [Solomon, S., D. Qin, M. Manning, Z. Chen, M. Marquis, K.B. Averyt, M.Tignor and H.L. Miller (eds.)]. Cambridge, United Kingdom and New York, NY, USA.

IEA (2007). World Energy Outlook 2007. Paris, International Energy Agency.

IEA (2010). World Energy Outlook 2010. Paris, International Energy Agency.

Johansson, D. J. A. (2011). "Temperature stabilization, ocean heat uptake and radiative forcing overshoot profiles." Climatic Change 108(1): 107-134.

Lucas, P. L., D. P. van Vuuren, J. G. J. Olivier, et al. (2007). "Long-term reduction potential of non-CO2 greenhouse gases." Environmental Science and Policy 10(2): 85-103.

Meinshausen, M., N. Meinshausen, W. Hare, et al. (2009). "Greenhouse-gas emission targets for limiting global warming to $2^{\circ} \mathrm{C}$." Nature 458(7242): 1158-1162.

Meinshausen, M., S. C. B. Raper and T. M. L. Wigley (2011a). "Emulating coupled atmosphereocean and carbon cycle models with a simpler model, MAGICC6 - Part 1: Model description and calibration." Atmospheric Chemistry and Physics 11(4): 1417-1456.

Meinshausen, M., S. J. Smith, K. Calvin, et al. (2011b). "The RCP greenhouse gas concentrations and their extensions from 1765 to 2300." Climatic Change 109(1): 213241.

Nordhaus, W. D. (2010). "Economic aspects of global warming in a post-Copenhagen environment." Proceedings of the National Academy of Sciences of the United States of America 107(26): 11721-11726.

Rogelj, J., C. Chen, J. Nabel, et al. (2010). "Analysis of the Copenhagen Accord pledges and its global climatic impacts- a snapshot of dissonant ambitions." Environmental Research Letters 5(3).

Rogelj, J., W. Hare, J. Lowe, et al. (2011). "Emission pathways consistent with a $2^{\circ} \mathrm{C}$ global temperature limit." Nature Climate Change 1: 413-418.

Solomon, S., D. Qin, et al. (2007). Technical Summary. In: Climate Change 2007: The Physical Science Basis. Contribution of Working Group I to the FourthAssessment Report of the Intergovernmental Panel on Climate Change [Solomon, S., D. Qin, M. Manning, Z. Chen, M. Marquis, K.B. Averyt, M. Tignor and H.L. Miller (eds.)]. Cambridge, United Kingdom and New York, NY,USA., Cambridge University Press.

UNEP (2010). "The Emissions Gap Report, Are the Copenhagen Accord Pledges Sufficient to Limit Global Warming to $2^{\circ} \mathrm{C}$ or $1.5^{\circ} \mathrm{C}$ ?".

UNEP (2011). Bridging the Emissions Gap, United Nations Environment Program (UNEP). 
UNFCCC (2009). "Decision 2/CP.15 Copenhagen Accord, pp. 4-10." http://unfccc.int/resource/docs/2009/cop15/eng/107.pdf.

UNFCCC (2010a). Information provided by Parties relating to Appendix I of the Copenhagen Accord, Retrieved March 15, 2010. http://unfccc.int/home/items/5264.php.

UNFCCC (2010b). Information provided by Parties relating to Appendix II of the Copenhagen Accord, Retrieved March 15, 2010. http://unfccc.int/home/items/5265.php.

UNFCCC (2010c). Report of the Conference of the Parties on its sixteenth session, held in Cancun from 29 November to 10 December 2010. Addendum. Part Two: Action taken by the Conference of the Parties at its sixteenth session. Decision 1/CP.16: The Cancun Agreements: Outcome of the work of the Ad Hoc Working Group on Long-term Cooperative Action under the Convention. FCCC/CP/2010/7/Add.1.

UNFCCC (2011). Report of the Conference of the Parties on its seventeenth session, held in Durban from 28 November to 11 December 2011. Addendum. Part Two: Action taken by the Conference of the Parties at its seventeenth session. Decision 2/CP.17: Outcome of the work of the Ad Hoc Working Group on Long-term Cooperative Action under the Convention. FCCC/CP/2011/9/Add.1.

van Vuuren, D. P. (2007). Energy Systems and Climate Change. Scenarios for an Uncertain Future, Science, Technology and Society. Utrecht, Utrecht University.

van Vuuren, D. P., E. Stehfest, M. G. J. den Elzen, et al. (2010). "Exploring IMAGE model scenarios that keep greenhouse gas radiative forcing below $3 \mathrm{~W} / \mathrm{m} 2$ in $2100 . "$ Energy Economics 32(5): 1105-1120.

van Vuuren, D. P. and K. Riahi (2011). "The relationship between short-term emissions and long-term concentration targets." Climatic Change 104(3-4): 793-801. 


\section{Emissions}

without BECCS

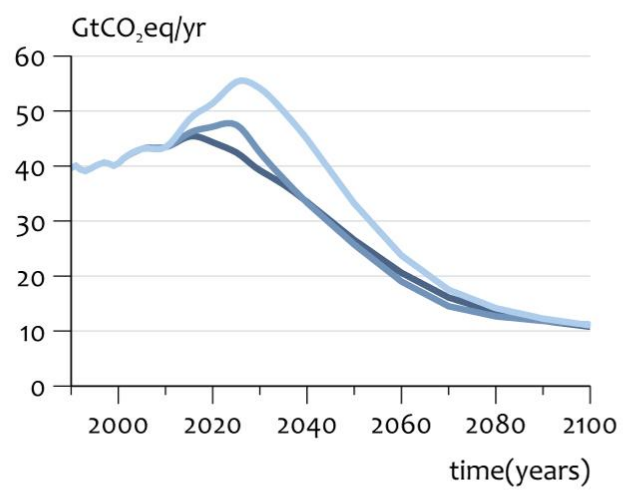

with BECCS

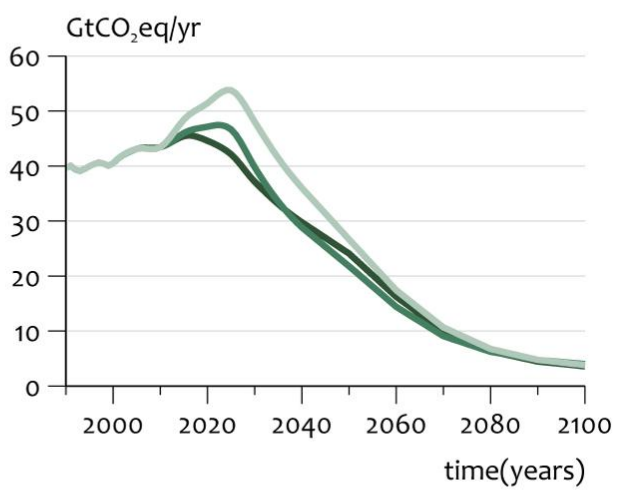

\section{Radiative forcing}

without BECCS

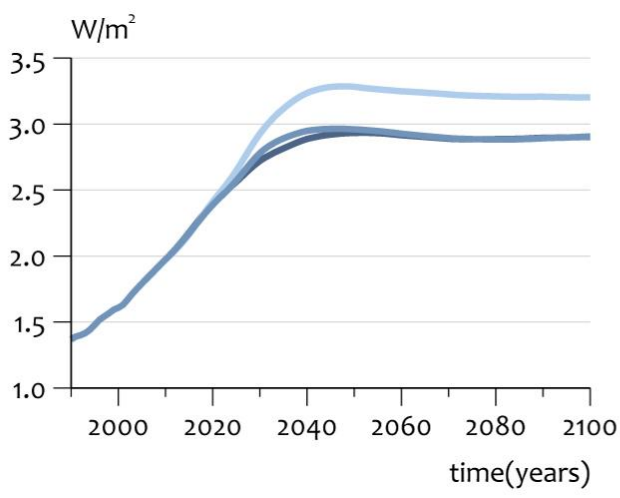

with BECCS

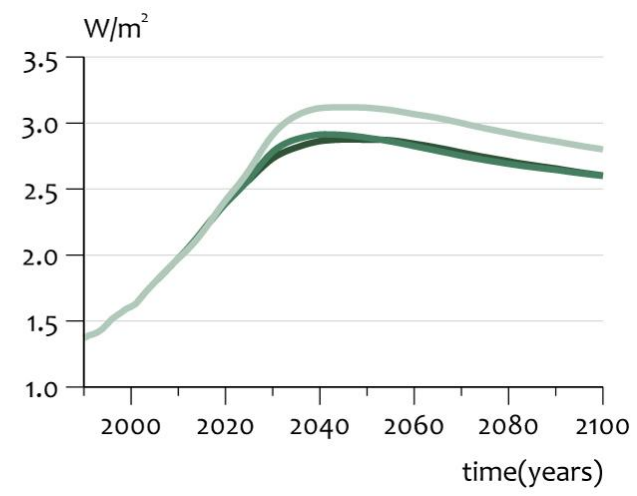

\section{Global mitigation costs}

without BECCS

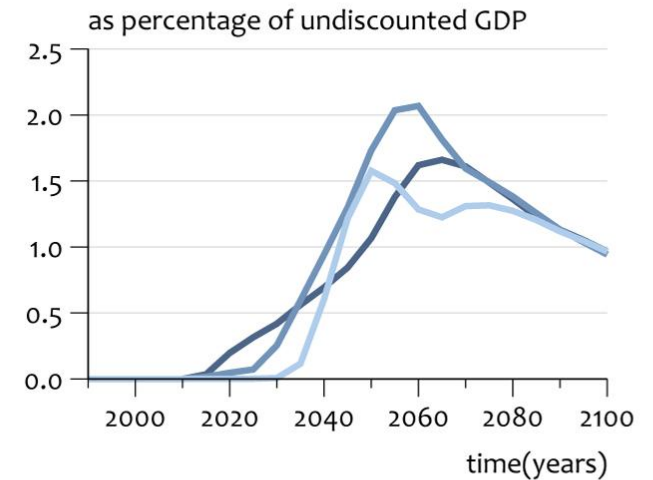

- optimal $2.9 \mathrm{~W} / \mathrm{m}^{2}$

- Potential Copenhagen $2.9 \mathrm{~W} / \mathrm{m}^{2}$

- Current Copenhagen $3.2 \mathrm{~W} / \mathrm{m}^{2}$ with BECCS

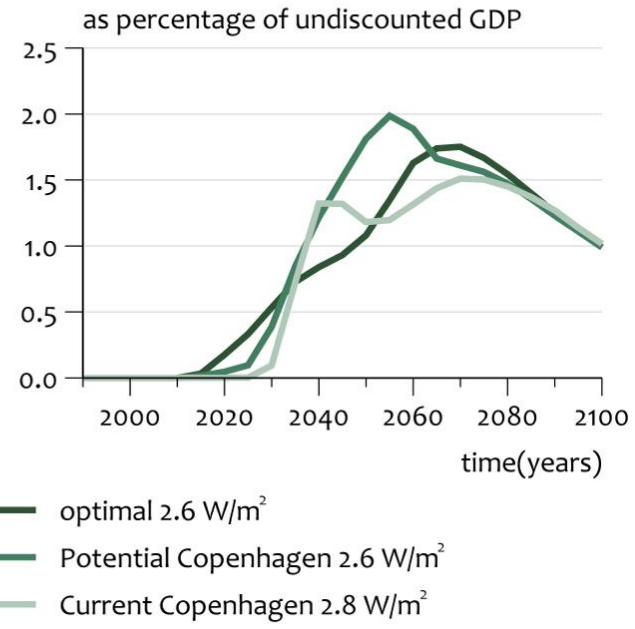




\section{Global-mean temperature increase above pre-industrial}

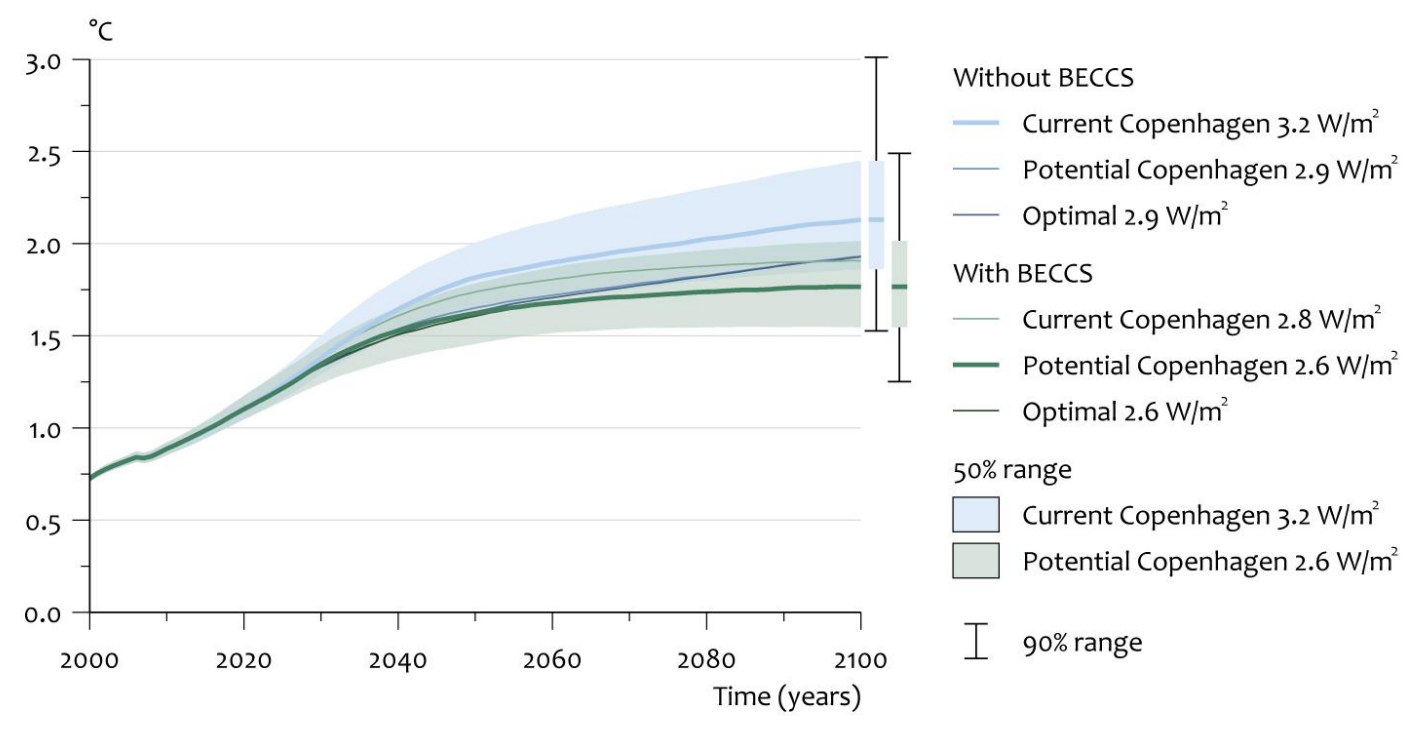




\section{Global emission pathways under different discount rates}

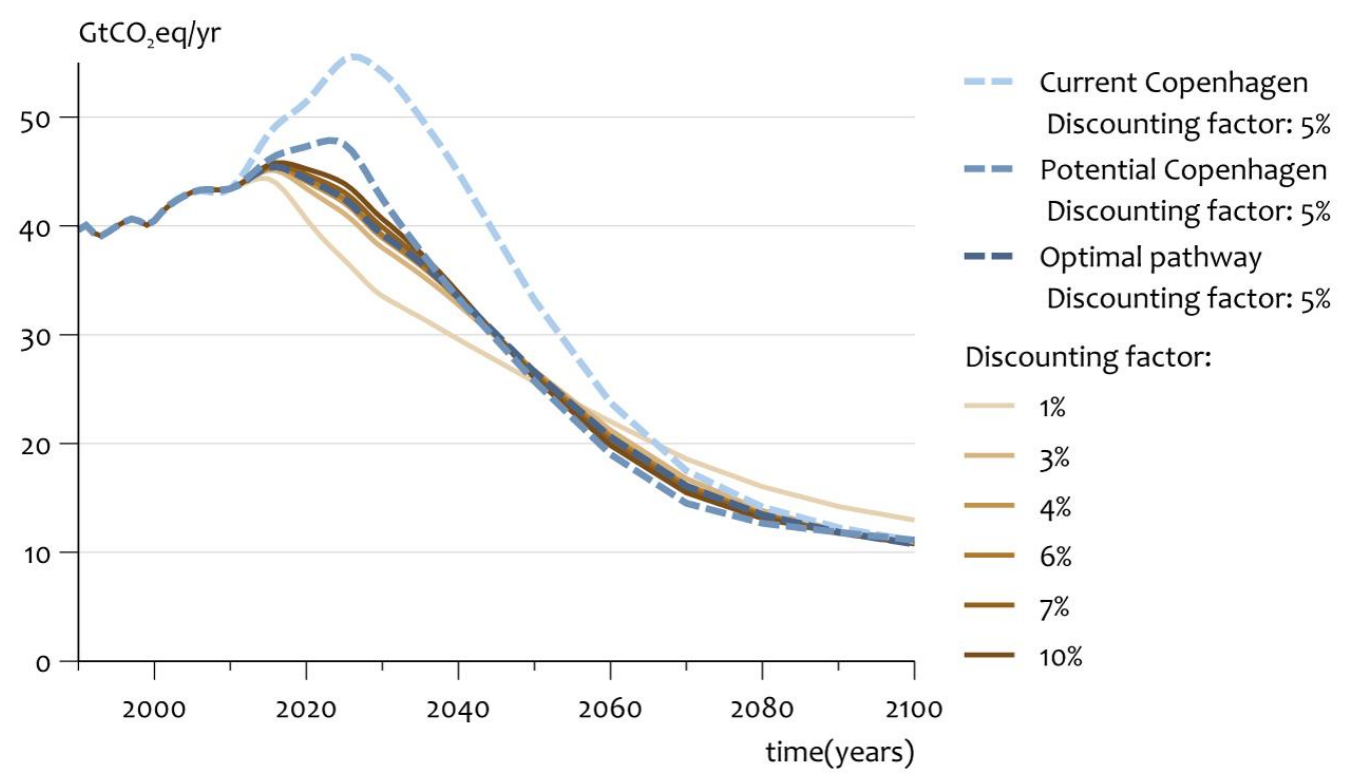




\section{University Library}

\section{- M M N E R VA A gateway to Melbourne's research publications}

Minerva Access is the Institutional Repository of The University of Melbourne

\section{Author/s:}

van Vliet, J;van den Berg, M;Schaeffer, M;van Vuuren, DP;den Elzen, M;Hof, AF;Beltran, AM;Meinshausen, $M$

Title:

Copenhagen Accord Pledges imply higher costs for staying below 2A degrees $\mathrm{C}$ warming $\mathrm{A}$ Letter

Date:

2012-07-01

Citation:

van Vliet, J., van den Berg, M., Schaeffer, M., van Vuuren, D. P., den Elzen, M., Hof, A. F., Beltran, A. M. \& Meinshausen, M. (2012). Copenhagen Accord Pledges imply higher costs for staying below 2A degrees C warming A Letter. CLIMATIC CHANGE, 113 (2), pp.551-561. https://doi.org/10.1007/s10584-012-0458-9.

Persistent Link:

http://hdl.handle.net/11343/283185 